\title{
PENGARUH METODE IMPROVE TERHADAP KREATIFITAS KEMAMPUAN KOMUNIKASI MATEMATIS DAN HASIL BELAJAR SISWA KELAS VII A MTS SYEKH SUBAKIR PADA MATERI BANGUN DATAR
}

\author{
Muhalizah \\ Institut Agama Islam Negeri (IAIN) Tulungagung \\ muhaliza997@gmail.com
}

\begin{abstract}
ABSTRAK
Matematika merupakan salah satu disiplin ilmu yang dipelajari dan diajarkan pada jenjang pendidikan mulai dari sekolah dasar hingga perguruan tinggi. Hal ini dikarenakan matematika merupakan salah satu ilmu dasar yang harus dikuasai setiap siswa untuk dibekali dengan kemampuan berfikir logis, analisis, sistematis, kritis dan kreatif serta kemampuan bekerjasama (Depdiknas, 2006: 153). Penelitian ini bertujuan untuk mengetahuiada tidaknya pengaruh Metode PembelajaranImprove terhadap kreatifitas kemampuan komunikasi matematis dan hasil belajar bagi siswa kelas VII A Mts Syekh Subakir 01 Nglegok Blitar. Metode pembelajaran IMPROVE merupakan akronim dari Introducing, the new concept, Matacognitive questioning, Practicing, Reviewing and reducing difficulties, Obtaining mastery, Verification, dan Enrichment. Populasi penelitian ini adalah semua siswa kelas VII A Mts Syekh Subakir 01 Nglegok Blitar. Sampel dalam penelitian ini diambil dengan Teknik Cluster Random Sampling dengan banyak siswa 32 sebagai kelas kontrol dan kelas eksperimen. Desain penelitian ini adalah True-Experimental Design bentuk Posttest-Only Control Derign. Rata-rata hasil test kratifitas kemampuan komunikasi matematis siswa pada kelas kontrol sebesar 80,03 dengan standar deviasi 10,918kelas ekperimen sebesar 86,25 dengan standar deviasi 6,951. Adapun rata-rata hasil belajar siswa pada kelas kontrol sebesar 79,44 dengan standar deviasi 10,531 dan kelas ekperimen sebesar 87,91 dengan standar deviasi 7,498. Nilai signifikansi model pembelajaran Metode Improve, $\mathrm{x}$, terhadap kratifitas kemampuan komunikasi matematis $\left(\mathrm{y}_{1}\right)$ sebesar $0,009<0,05$. Hal ini berarti model pembelajaran Metode Improve, $\mathrm{x}$, berpengaruh terhadap kreatifitas kemampuan komunikasi matematis $\left(\mathrm{y}_{1}\right)$. Dapat disimpulkan bahwa kreatifitas kemampuan komunikasi matematis siswa kelas kontrol lebih baik dari kratifitas kemampuan komunikasi matematis kelas eksperimen. Adapun nilai signifikansi model pembelajaran Metode Improve, $\mathrm{x}$, terhadap hasil belajar siswa $\left(\mathrm{y}_{2}\right)$ sebesar $0.000<0.05$. Hal ini berarti model pembelajaran Metode Improve, $\mathrm{x}$, berpengaruh terhadap hasil belajar siswa $\left(\mathrm{y}_{2}\right)$. Dapat disimpulkan bahwa hasil belajar siswa kelas eksperimen lebih baik dari hasil belajar siswa kelas kontrol.
\end{abstract}

Kata kunci: hasil belajar siswa, kreatifitas kemampuan komunikasi matematis, metode pembelajaran Improve

\begin{abstract}
Mathematics is one of the disciplines learned and taught at the education level from elementary school to college. This is because mathematics is one of the basic science that must be mastered by each student to be equipped with logical, analytical, systematic, critical and creative thinking ability and cooperation (Depdiknas, 2006: 153). This study aims to determine whether there is influence Improve Learning Method on creativity of mathematical communication skills and learning outcomes for students of class VII A Mts Sheikh Subakir 01 Nglegok Blitar. IMPROVE learning method is an acronym of Introducing, the new concept, Matacognitive questioning, Practicing, Reviewing and reducing difficulties, Obtaining mastery, Verification, and Enrichment. The population of this study are all students of class VII A Mts Sheikh Subakir 01 Nglegok Blitar. The sample in this study was taken with the Random Sampling Cluster Technique with many students 32 as the control class and experimental class. The design of this research is
\end{abstract}


True-Experimental Design form Posttest-Only Control Derign. The average of categorical test of students' mathematical communication ability in control class is 80,03 with standard deviation of 10.918 experiment class is 86,25 with standard deviation 6,951 . The average of student learning outcomes in the control class is 79.44 with standard deviation of 10,531 and experimental class equal to 87,91 with standard deviation of 7,498. The value of significance of learning model of Improve Method, $x$, to cratification of mathematical communication ability $\left(y_{1}\right)$ is $0,009<0,05$. This means that the learning model of Improve Method, $x$, influences the creativity of mathematical communication skills $\left(y_{1}\right)$. It can be concluded that the creativity of students' mathematical communication ability of the control class is better than the cratification of the mathematical communication ability of the experimental class. As for the significance value of the Improve, $\mathrm{x}$, method of learning towards student learning outcomes $\left(y_{2}\right)$ of $0.000<0.05$. This means that learning model of Improve Method, $x$, has an effect on student's learning result $\left(y_{2}\right)$. It can be concluded that the learning outcomes of the experimental class students are better than the student's learning outcomes of the control class.

Keywords: student learning outcomes, creativity of mathematical communication skills, improve learning methods

\section{PENDAHULUAN}

Matematika merupakan salah satu disiplin ilmu yang dipelajari dan diajarkan pada jenjang pendidikan mulai dari sekolah dasar hingga perguruan tinggi. Hal ini dikarenakan matematika merupakan salah satu ilmu dasar yang harus dikuasai setiap siswa untuk dibekali dengan kemampuan berfikir logis, analisis, sistematis, kritis dan kreatif serta kemampuan bekerjasama (Depdiknas, 2006: 153). Matematika memiliki fungsi yaitu mengembangkan kemampuan menghitung, mengukur, dan memecahkan masalah dalam kehidupan sehari-hari (Verowita, 2012). Matematika mempunyai peran penting dalam segala aspek kehidupan sehingga matematika harus diberikan sejak dini pada siswa dan proses ini disebut pembelajaran matematika.

Pembelajaran matematika adalah proses pemberian pengalaman belajar kepada siswa melalui serangkaian kegiatan yang terencana sehingga siswa memperoleh kompetensi tentang bahan matematika yang dipelajari (Mushsetyo, 2011). Pembelajaran matematika merupakan proses dimana siswa secara aktif mengkontruksi pengetahuan matematika (Suherman dan Fitri, 2014). Hal ini bermakna bahwa pembelajaran matematika akan lebih baik jika siswa mampu mengkontruksi melalui pengalaman dimana siswa terlibat secara aktif dalam kegiatan pembelajaran marematika. Secara umum, tujuan pembelajaran matematika adalah mengembangkan sikap kritis, kreatif dan rasional yang dimiliki oleh siswa. Tujuan pembelajaran matematika di Mts Syekh Subakir 01 


\section{Pengaruh Metode Improve terhadap Kreatifitas Kemampuan Komunikasi Matematis dan Hasil}

Belajar Siswa Kelas VII A MTS Syekh Subakir pada Materi Bangun Datar

Nglegok Blitar menurut Permendiknas No. 22 Tahun 2006 tentang Standar Isi Mata Pelajaran Matematika adalah agar para siswa Mts Syekh Subakir 01 Nglegok Blitar dapat memahami konsep matematika, menjelaskan keterkaitan antar konsep dan pemecahan masalah.Dalam pengajaran matematika diharapkan siswa benar-benar aktif, sehingga akan berdampak pada ingatan siswa tentang apa yang telah dipelajari. Suatu konsep akan mudah dipahami dan mudah diingat oleh siswa apabila konsep tersebut disajikan melalui prosedur dan langkah-langkah yang tepat, jelas dan menarik. Komunikasi matematika siswa dalam belajar matematika merupakan salah satu faktor yang mempengaruhi keberhasilan dalam belajar matematika. Salah satu kegiatan belajar yang menekankan berbagai kegiatan tindakan adalah menggunakan pendekatan tertentu dalam pembelajaran, karena suatu pendekatan dalam pembelajaran pada hakikatnya merupakan cara yang teratur dan terfikir secara sempurna untuk mencapai suatu tujuan pengajaran dan untuk memperoleh kemampuan dalam mengembangkan efektifitas belajar yang dilakukan oleh pendidikan dan peserta didik. Pendekatan ini merupakan peran yang sangat penting untuk menentukan berhasil atau tidaknya pembelajaran yang diinginkan (Rini Handayani, 2010).

Untuk mengantisipasi masalah tersebut yang berkelanjutan maka perlu dicarikan formula pembelajaran yang tepat, sehingga dapat meningkatkan komunikasi matematika siswa dalam pembelajaran matematika. Para guru terus berusaha menyusun dan menerapkan berbagai model pembelajaran yang bervariasi agar siswa tertarik dan bersemangat dalam belajar matematika.Salahsatu cara meningkatkan komunikasi matematika siswa adalah menerapkan metodeImprove dengan menggunakan media computer. Hakikat metode Improve adalah pembelajaran dengan menggunakan penekanan pada proses pembentukan suatu konsep dan memberikan kesempatan luas kepada siswa untuk berperan aktif dalam proses tersebut Derek Glover (2005:12).

Berdasarkan latar belakang dan permasalahan diatas maka dapat dirumuskan tujuan penelitian ini adalah untuk mengetahui ada tidaknya pengaruh Metode Pembelajaran IMPROVE terhadap kreatifitas kemampuan komunikasi matematis dan hasil belajar siswakelas VII A Mts Syekh Subakir 01 Nglegok Blitar. 


\section{KAJIAN PUSTAKA}

Untuk memperoleh pengertian yang benar dan untuk menghindari kesalahan pemahaman judul penelitian ini, maka akan diuraikan secara singkat beberapa kajian pustaka sebagai berikut

a. Metode Improve

Metode pembelajaran IMPROVE merupakan akronim dari Introducing the new concepts, Metacognitive questioning, Practicing, Reviewing and reducing difficulties, Obtaining mastery, Verification, and Enrichment (Mevarech dan Kramarski, 1997). Langkah-langkah metode pembelajaran IMPROVE antara lain (1) Menghantarkan konsep-konsep baru (Introducing the new concepts), guru membimbing siswa menemukan suatu konsep dengan memberikan pertanyaanpertanyaan yang mengarah pada penemuan suatu konsep sehingga pemahaman siswa terhadap suatu konsep dapat bertahan lebih lama karena siswa turut aktif menemukan dan memahami konsep baru; (2) Mengajukan pertanyaan metakognitif (Metacognitive questioning), metakognitif adalah pengetahuan seseorang tentang proses berpikirnya sendiri dan kemampuan seseorang dalam mengontrol aktivitas kognitifnya dalam belajar (Setyadi, 2014). Pertanyaanpertanyaan metakognitif meliputi pertanyaan pemahaman, strategi, koneksi, dan refleksi; (3) Berlatih (Practicing), guru memberikan latihan kepada siswa secara kelompok dalam bentuk soal-soal yang terdiri dari pertanyaan-pertanyaan metakognitif.; (4) Mengulas dan mereduksi 4 kesulitan (Reviewing and reducing difficulties), pada tahap ini guru melakukan pengulasan atau pembahasan terhadap kesulitan-kesulitan yang dialami siswa sewaktu memahami materi atau menjawab soal-soal, guru dapat melakukan hal ini dengan diskusi kelas, selanjutnya guru memberikan solusi guna menjawab kesulitan-kesulitan yang dialami siswa; (5) Penguasaan materi (Obtaining mastery), pada tahap ini guru akan mengetahui tingkat penguasaan materi siswa secara individu atau keseluruhan, hal ini dapat dilakukan dengan memberikan tes kepada siswa sesuai dengan materi yang telah dipelajari; (6) Melakukan verifikasi (Verification), guru mengidentifikasi siswa yang telah memahami atau menguasai materi dan siswa yang belum menguasai materi dengan melihat hasil tes yang telah diberikan pada tahap sebelumnya; dan (7) Pengayaan (Enrichment), guru memberikan respon terhadap hasil verifikasi, 


\section{Pengaruh Metode Improve terhadap Kreatifitas Kemampuan Komunikasi Matematis dan Hasil Belajar Siswa Kelas VII A MTS Syekh Subakir pada Materi Bangun Datar}

siswa yang telah menguasai materi dapat diberikan soal-soal pengayaan dan yang belum menguasai diberikan pengulangan (Huda, 2013). Kelemahan metode IMPROVE adalah guru harus mempunyai strategi khusus agar semua peserta didik dapat mengikuti langkah-langkah yang ada dalam metode pembelajaran ini membutuhkan waktu yang relatif lama (Amelia, 2014). Kelebihannya adalah siswa menjadi lebih aktif dalam pembelajaran, mengoptimalkan kemampuan berpikir siswa, suasana pembelajaran tidak membosankan, dan memberikan kesempatan kepada siswa untuk mengeksploitasi ide-idenya melalui latihanlatihan yang diberikan (Herdian dalam Fariski, 2012).

b. Kreatifitas Kemampuan Komunikasi Matematis

Kratifitas kemampuan komunikasi matematis adalah suatu kratifitas kemampuan yang dimiliki siswa berupa cara yang digunakan siswa untuk menyatakan dan menafsirkan gagasan-gagasan matematika secara lisan maupun tertulis, baik dalam bentuk gambar, tabel, diagram, rumus, ataupun demonstrasi. (Hodiyanto, 2018)

c. Hasil Belajar

Hasil belajar merupakan tolak ukur untuk melihat keberhasilan peserta didik dalam menguasai materi pelajaran yang disampaikan selama pembelajaran. Hasil belajar peserta didik dapoat dilihat dari kemampuannya dalam meningkat pelajaran yang telah disampaikan selama pembelajaran dan bagaimana peserta didik tersebut bisa menerapkannya serta mampu memecahkan masalah yang timbul sesuai dengan apa yang telah dipelajarinya. Hasil belajar matematika yang dimaksud disini adalah hasil belajar kognitif yang diperoleh pesertadidik sebelum dan sesudah mengalamiproses pembelajaran matematika dengan menggunakan metode pembelajaran improve dalam setiap aktivitas yang dilakukan oleh peserta didik.

\section{METODE PENELITIAN}

Jenis Penelitian ini adalah penelitian eksperimen dengan rancangan penelitian yang digunakan yaitu True-Experimental Design bentuk Posttest-Only Control Design. Desain penelitian ini menggunakan pretest sebelum diberi perlakuan, dengan demikian, hasil perlakuan dapat diketahui lebih akurat, karena 
dapat membandingkan antara keadaan sebelum diberi perlakuan dan sesudah diberi perlakuan.

Populasi dalam penelitian ini adalahseluruh siswa kelas VII Mts Syekh Subakir 01 Nglegok Blitar tahun ajaran 2017/2018. Pengambilan sampel dengan menggunakan Teknik Cluster Random Sampling dengan banyak siswa 32 sebagai kelas kontrol dan kelas eksperimen, dimana sampel dipilih berdasarkan karakteristik tertentu yang disesuaikan dengan kebutuhan data dalam penelitian, dengan kelas control berjumlah 32 siswa dan eksperimen 32 siswa.

Dalam penelitian ini terdapat 2 variabel, yaitu variable bebas dan variable terikat. Variable bebas daripenelitian ini yaitu Metode Improve. Sedangkan variable terikatnya yaitu kratifitas kemampuan komunikasi matematis siswa dan hasil belajar siswa.

Teknik pengumpulan data dengan memberikan post-test kepada kelas kontrol dan eksperimen. Post-test diberikan untuk mengukur kemampuan komunikasi matematis dan hasil belajar siswa. Berdasarkan hal tersebut diperoleh data primer berupa data interval nilai test kemmapuan komunikasi matematis dan hasil belajar siswa.Teknis analisis data dalam penelitian ini melalui beberapa uji, yaitu uji Asumsi Klasik dan uji Hipotesis dengan menggunakan uji-t.

\section{HASIL DAN PEMBAHASAN}

Penelitian ini bertujuan untuk mengetahui ada tidaknya pengaruh metode pembelajaran IMPROVE terhadap kreatifitas kemampuan komunikasi matematis dan hasil belajar bagi siswa kelas VII Mts Syekh Subakir. Penelitian ini dilakukan pada kelas VII A yang terdiridari kelas kontrol dan kelas eksperimen. Pembelajaran matematika pada kelas kontrol diberi perlakuan dengan metode yang sering digunakan oleh guru yaitu metode instruksional. Yamin (2007) menyatakan bahwa metode instruksional adalah cara melakukan atau menyajikan, menguraikan, memberi contoh, dan memberi latihan isi pelajaran kepada siswa untuk mencapai tujuan tertentu. Metode instruksional yang digunakan pada kelas kontrol adalah metode ceramah dan drill (latihan) sedangkan kelas eksperimen diberi perlakuan dengan metode pembelajaran IMPROVE. 


\section{Pengaruh Metode Improve terhadap Kreatifitas Kemampuan Komunikasi Matematis dan Hasil Belajar Siswa Kelas VII A MTS Syekh Subakir pada Materi Bangun Datar}

Tahap Metacognitive questioning, guru memberikan pertanyaanpertanyaan metakognitif yang bertujuan untuk mendorong siswa supaya memiliki kemampuan yang tinggi dalam pemecahan masalah. Pertanyaan-pertanyaan metakognitif membantu siswa dalam menyelesaikan permasalahan yang diberikan namun ada beberapa siswa yang merasa kesulitan dengan pertanyaan tersebut. Tahap Practicing, guru memberikan latihan secara kelompok dalam bentuk soalsoal yang terdiri dari pertanyaan metakognitif yang diberikan dalam lembar kerja kelompok.

Proses pembelajaran matematika yang dilakukan secara berkelompok berbeda dengan proses pembelajaran matematika yang biasa dilakukan guru di kelas. Hal ini dikarenakan belajar secara kelompok terdiri dari dua orang atau lebih yang akan menciptakan pola interaksi yang optimal, mengembangkan semangat kebersamaan, timbulnya motivasi serta menumbuhkan komunikasi yang efektif (Verowita, 2012). Dampaknya adalah memberikan suasana baru yang menyenangkan dalam pembelajaran matematika yang selama ini siswa menganggap bahwa pembelajaran matematika membosankan dan siswa menjadi lebih antusias dan aktif dengan adanya diskusi kelompok dimana siswa memberikan ide-idenya masing-masing dalam menyelesaikan permasalahan. Selain itu, siswa juga menjadi lebih kritis dan teliti dalam membaca permasalahan yang diberikan sehingga dapat menemukan penyelesaian yang tepat. Hal ini dikarenakan dalam metode pembelajaran IMPROVE terdapat aktivitas-aktivitas yang mendorong adanya interaksi antar siswa. Hal ini sejalan dengan penelitian Megasari (2016) yang menyatakan bahwa melibatkan siswa secara aktif dalam proses pembelajaran dapat meningkatkan hasil belajar. Namun pada saat diskusi kelompok beberapa siswa membuat gaduh sehingga suasana kelas menjadi kurang kondusif. Guru mengatasi situasi tersebut dengan menyuruh salah satu kelompok untuk maju menuliskan jawaban hasil diskusi di depan kelas dan memberikan reward. Siswa menjadi antusias dan kelas dapat dikondisikan menjadi kondusif untuk belajar. Waktu yang digunakan selama pembelajaran relatif lama karena banyak tahapan dari metode pembelajaran IMPROVE yang harus dilakukan.

Tahap Reviewing and reducing difficulties, guru memberikan pengulasan atau penjelasan kembali ketika siswa mengalami kesulitan sehingga siswa dapat 
memahami materi yang sedang dijelaskan. Kemudian tahap Obtaning mastery, guru memberikan kuis untuk mengukur pemahaman siswa terkait materi yang telah dipelajari. Pemberian pengulasan dan kuis memberikan dampak positif terhadap pemahaman siswa yang lebih baik dan juga terhadap hasil belajar matematika siswa. Tahap Verification, guru melakukan verifikasi yang dilakukan dengan koreksi bersama-sama siswa untuk mengetahui hasil kuis yang telah dikerjakan. Siswa yang belum mencapai KKM atau belum tuntas akan diberikan soal remidial sedangkan siswa yang sudah mencapai KKM atau tuntas akan diberikan soal pengayaan dan tahap ini yang disebut dengan tahap Enrichment.

Berdasarkan uraian di atas, pembelajaran matematika dengan menggunakan metode pembelajaran IMPROVE memiliki pengaruh terhadap hasil belajar matematika siswa. Hal tersebut terlihat dari perbedaan hasil belajar antara siswa dengan kelas yang diberikan perlakuan metode pembelajaran IMPROVE dengan siswa dengan kelas yang diberi metode pembelajaran instruksional. Hasil belajar matematika siswa pada kelas eksperimen lebih tinggi dibandingkan kelas kontrol. Oleh karena itu, penggunaan metode pembelajaran IMPROVE berpengaruh terhadap hasil belajar matematika siswa kelas VII Mts Syekh Subakir 01 Nglegok Blitar.

Berikut hasil uji statistik:

\section{Uji Asumsi Klasik}

a. Uji Normalitas

\begin{tabular}{|c|c|c|c|c|c|c|c|}
\hline & \multirow[b]{2}{*}{ treatment } & \multicolumn{3}{|c|}{ Kolmogorov-Smirnove } & \multicolumn{3}{|c|}{ Shapiro-Wilk } \\
\hline & & Statistic & $\mathrm{df}$ & Siq. & Statistic & $\mathrm{df}$ & Siq. \\
\hline \multirow[t]{2}{*}{$\mathrm{KKKM}$} & pretest & .131 & 32 & .173 & .960 & 32 & .270 \\
\hline & posttest & .119 & 32 & $.200^{\circ}$ & .960 & 32 & .279 \\
\hline \multirow[t]{2}{*}{ Hasil Belajar } & pretest & .142 & 32 & .102 & .962 & 32 & .307 \\
\hline & posttest & .135 & 32 & .143 & .946 & 32 & .110 \\
\hline
\end{tabular}

Berdasarkan output spss di atas, diperoleh nilai signifikansi kemampuan komunikasi matematis siswa baik kelas kontrol ataupun kelas eksperimen lebih besar dari 0,05. Hal ini berarti kemampuan komunikasi matematis siswa kelas control dan eksperimen berdistribusi normal. Adapun nilai signifikansi hasil belajar siswa kelas kontrol dan 
eksperimen juga lebih besar dari 0,05 . Hal ini hasil belajar siswa kelas

kontrol dan eksperimen berdistribusi normal.

\section{Uji Hipotesis}

Pada penelitian ini, terdapat satu variabel bebas (x) yaitu Metode Improve dan dua variabel terikat yaitu kemampuan komunikasi matematis $\left(\mathrm{y}_{1}\right)$ dan hasil belajar siswa $\left(\mathrm{y}_{2}\right)$. Uji hipotesis dilakukan menggunkan software SPSS 16.0 for windows. Berdasarkan perhitungannya diperoleh hasil sebagai berikut :

Between-Subjects Factors

\begin{tabular}{|ll|l|r|}
\hline & & Value Label & \multicolumn{1}{|c|}{$\mathbb{N}$} \\
\hline treatment & 1 & pretest & 32 \\
& 2 & posttest & 32 \\
\hline
\end{tabular}

Berdasarkan tabel di atas diketahui bahwa jumlah siswa dalam kelas control sebanyak 32 siswa. Jumlah siswa kelas eksperimen yaitu 32 siswa.

Descriptive Statistics

\begin{tabular}{|ll|r|r|r|}
\hline & treat. & \multicolumn{1}{|c|}{ Mean } & Std. Deviation & \multicolumn{1}{|c|}{$\mathrm{N}$} \\
\hline KKKM & pretest & 80.03 & 10.918 & 32 \\
& posttest & 86.25 & 6.951 & 32 \\
& Total & 83.14 & 9.605 & 64 \\
\hline Hasil Belajar & pretest & 79.44 & 10.531 & 32 \\
& posttest & 87.91 & 7.498 & 32 \\
& Total & 83.67 & 10.022 & 64 \\
\hline
\end{tabular}

Berdasarkan tabel di atas diketahui rata-rata hasil test kratifitas kemampuan komunikasi matematis siswa pada kelas kontrol sebesar 80,03 dengan standar deviasi 10,918. Sedangkan rata-rata hasil test kreatifitas kemampuan komunikasi matematis siswa pada kelas ekperimen sebesar 86,25 dengan standar deviasi 6,951. Adapun rata-rata hasil belajar siswa pada kelas kontrol sebesar 79,44 dengan standar deviasi 10,531. Sedangkan rata-rata hasil belajar siswa pada kelas ekperimen sebesar 87,91 dengan standar deviasi 7,498 . 


\section{Muhalizah}

\begin{tabular}{|c|c|c|c|c|c|c|}
\hline \multicolumn{7}{|c|}{ Multivariate Tests ${ }^{\text {b }}$} \\
\hline Effect & & Value & $\mathrm{F}$ & Hypothesis df & Error df & Sig. \\
\hline \multirow[t]{4}{*}{ Intercept } & Pillai's Trace & .993 & $4.294 \mathrm{E} 3^{3}$ & 2.000 & 61.000 & .000 \\
\hline & Wilks' Lambda & .007 & $4.294 \mathrm{E} 3^{2}$ & 2.000 & 61.000 & .000 \\
\hline & Hotelling's Trace & 140.784 & $4.294 \mathrm{E}^{2}$ & 2.000 & 61.000 & .000 \\
\hline & Roy's Largest Root & 140.784 & $4.294 \mathrm{E} 3^{2}$ & 2.000 & 61.000 & .000 \\
\hline \multirow[t]{4}{*}{$x$} & Pillai's Trace & .221 & $8.631=$ & 2.000 & 61.000 & .001 \\
\hline & Wilks' Lambda & .779 & $8.631=$ & 2.000 & 61.000 & .001 \\
\hline & Hotelling's Trace & .283 & $8.631^{=}$ & 2.000 & 61.000 & .001 \\
\hline & Roy's Largest Root & .283 & $8.631^{2}$ & 2.000 & 61.000 & .001 \\
\hline
\end{tabular}

Berdasarkan tabel diatas menunjukkan bahwa harga F untuk Pillai's Trace, Wilks' Lambda, Hotelling's Trace dan Roy's Largest Root memliki nilai signifikansi lebih kecil dari 0,05. Nilai signifikansi sebesar 0.001 menunjukkan bahwa harga F untuk Pillai's Trace, Wilks' Lambda, Hotelling's Trace dan Roy's Largest Root siginifikan. Sehingga dapat disimpulkan bahwa model pembelajaran Metode Improve berpengaruh terhadap kreatifitas kemampuan komunikasi matematis dan hasil belajar siswa.

Tests of Between-Subjects Effects

\begin{tabular}{|ll|r|r|r|r|r|}
\hline Source & $\begin{array}{l}\text { Dependent } \\
\text { Variable }\end{array}$ & $\begin{array}{c}\text { Type III Sum } \\
\text { of Squares }\end{array}$ & \multicolumn{1}{c|}{ df } & Mean Square & \multicolumn{1}{c|}{ F } & \multicolumn{1}{c|}{ Sig. } \\
\hline Corrected Model & KKKM & $618.766^{\circ}$ & 1 & 618.766 & 7.388 & .009 \\
& Hasil Belajar & $1147.516^{\mathrm{b}}$ & 1 & 1147.516 & 13.733 & .000 \\
\hline Intercept & KKKM & 442391.266 & 1 & 442391.266 & $5.282 \mathrm{E} 3$ & .000 \\
& Hasil Belajar & 448062.891 & 1 & 448062.891 & $5.362 \mathrm{E} 3$ & .000 \\
\hline$x$ & KKKM & 618.766 & 1 & 618.766 & 7.388 & .009 \\
& Hasil Belajar & 1147.516 & 1 & 1147.516 & 13.733 & .000 \\
\hline Error & KKKM & 5192.969 & 62 & 83.758 & & \\
& Hasil Belajar & 5180.594 & 62 & 83.558 & & \\
\hline Total & KKKM & 448203.000 & 64 & & & \\
& Hasil Belajar & 454391.000 & 64 & & & \\
\hline Corrected Total & KKKM & 5811.734 & 63 & & & \\
& Hasil Belajar & 6328.109 & 63 & & & \\
\hline
\end{tabular}

\section{KESIMPULAN}

Berdasarkan tabel diatas diketahui nilai signifikansi model pembelajaran Metode Improve, $\mathrm{x}$, terhadap kratifitas kemampuan komunikasi matematis $\left(\mathrm{y}_{1}\right)$ sebesar 0,009 < 0,05. Hal ini berarti model pembelajaran Metode Improve, $\mathrm{x}$, berpengaruh terhadap kreatifitas kemampuan komunikasi matematis $\left(\mathrm{y}_{1}\right)$. Dapat disimpulkan bahwa kreatifitas kemampuan komunikasi matematis siswa kelas 
kontrol lebih baik dari kratifitas kemampuan komunikasi matematis kelas eksperimen. Adapun nilai signifikansi model pembelajaran Metode Improve, $\mathrm{x}$, terhadap hasil belajar siswa $\left(\mathrm{y}_{2}\right)$ sebesar $0.000<0.05$. Hal ini berarti model pembelajaran Metode Improve, $\mathrm{x}$, berpengaruh terhadap hasil belajar siswa $\left(\mathrm{y}_{2}\right)$. Dapat disimpulkan bahwa hasil belajar siswa kelas eksperimen lebih baik dari hasil belajar siswa kelas kontrol.

\section{DAFTAR PUSTAKA}

Amelia, Risma. 2014. Meningkatkan Kemampuan Pemahaman Matematik Siswa SMP Swasta di Kota Cimahi dengan Menggunakan Metode Pembelajaran IMPROVE. Prosiding Seminar Nasional Pendidikan Matematika STKIP Siliwangi Volume 2 tahun 2014. Diakses melalui: http://publikasi.stkipsiliwangi.ac.id/files/2014/12/Prosiding-

SemnasSTKIP2014.pdf pada tanggal 11 Agustus 2015 pukul 06.22 WIB.

Budiyono. 2003. Metodologi Penelitian Pendidikan. Surakarta: Sebelas Maret University Press.

Depdiknas. 2006. Permendiknas Nomor 22 Tahun 2006 tentang Standar Isi dan Proses Satuan Pendidikan Dasar dan Menengah. Jakarta: Depdiknas. Diakses melalui: http://asefts63.files.wordpress.com/2011/01/permendiknas-n0-22-tahun2006-standar isi.pdfpada tanggal 24 Oktober 2015 pukul 14.56 WIB.

Fariski, Mukhammad. 2012. Efektifitas metode pembelajaran IMPROVE dengan bantuan alatPeraga miniatur tandon air terhadap hasil belajar peserta didik pada materi logika matematika semester genap kelas X SMA Islam Sultan Agung 1 Semarang tahun pelajaran 2011/2012. Diakses melalui: http://eprints.walisongo.ac.id/397/ pada tanggal 20 Januari 2016 pukul 05.30 WIB.

Fitri, Rahma. 2014. Penerapan Strategi The Firing Line pada Pembelajaran Matematika Siswa Kelas XI IPS SMA Negeri 1 Batipuh. FMIPA jurusan matematika UNP. Jurnal Pendidikan Matematika Vol. 3 No. 1 (2014). Diakses melalui:http://ejournal.unp.ac.id/students/index.php/pmat/article/view/121 48 pada tanggal Januari 2016 pukul 19.12 WIB.

Huda, Miftahul. 2013. Model-model Pengajaran dan Pembelajaran: Isu-Isu Metodis dan Paradigmatis. Malang: Pustaka Pelajar.

Megasari, Yunita. 2016. Pengaruh Metode Pembelajaran IMPROVE dengan Penggunaan Kepala Bernomor terhadap Hasil Belajar Siswa Kelas XI APK 1 SMK Pemuda Papar Tahun Ajaran 2015/2016 pada Pokok Bahasan Matriks. FKIP Matematika Universitas Nusantara PGRI Kediri. Disakses melalui: http://simki.unpkediri.ac.id/ pada tanggal 11 Maret 2016 pukul 7.41 WIB.

Muhsetyo, Gatot dkk. 2011. Pembelajaran Matematika SD. Jakarta: Universitas Terbuka. 
Nawi, M. 2012. Pengaruh Strategi Pembelajaran dan Kemampuan Penalaran Formal Terhadap Hasil Belajar Matematika Siswa Sekolah Menengah Atas (Swasta) Al Ulum Medan.

Medan: Jurnal Tabularasa PPS UNIMED Volume 9 No. 1. Diakses melalui: http://digilib.unimed.ac.id/public/UNIMED-Article-23927-

M\%20Nawi.pdf pada tanggal 20 November 2015 pukul 18.09 WIB.

Purnamadewi, Jesyich Anjras. 2013. Keefektifan pembelajaran metode IMPROVE dengan pendekatan PMRI terhadap kemampuan pemecahan masalah siswa kelas VII materi segiempat. Skripsi. Semarang: FMIPA jurusan Mmatematika UNNES. Diakses melalui: http://lib.unnes.ac.id/17443/1/4101409012.pdf pada tanggal 3 Januari 2016 pukul 17.09 WIB.

Retnaning dan Susanah. 2014. Penerapan Pembelajaran dengan Metode IMPROVE pada Materi Pertidaksamaan di Kelas X-B SMAN 1 Kauman Tulungagung. Jurnal Ilmiah Pendidikan Matematika Volume 3 No. 2 Tahun 2014. Diakses melalui: http://ejournal.unesa.ac.id/ index.php/mathedunesa/article/view/8719 pada tanggal 1 Februari 2016 pukul 06.59 WIB.

Roestiyah, N.K. 2008. Strategi Belajar Mengajar. Jakarta: Rineka Cipta.

Sembiring. R. K. 2003. Analisis Regresi. Bandung: ITB.

Setyadi, Danang. 2014. Pengaruh Pembelajaran dengan Pendekatan Metakognitif terhadap Hasil Belajar Matematika Siswa Kelas VII SMP Negeri 2 Pabelan. Repository UKSW. Diakses melalui: http://repository.uksw.edu/handle/123456789/4960 pada tanggal 21 April 2016 pukul 16.01 WIB.

Verowita, Winda. 2012. Pengaruh Penerapan Model Pembelajaran Kooperatif TipeThink Pair Share Terhadap Pemahaman Konsep DalamPembelajaran Matematika. Vol. 1 No. 1(2012). Jurnal Pendidikan Matematika, Part 3 : Hal. 48-51. Diakses Melalui: http://ejournal.unp.ac.id/students/index.php/pmat/article/download/1177/8 69pada tanggal 21 Oktober 2015 Pukul 08.14 WIB.

Yamin, Martinis. 2007. Strategi Pembelajaran Berbasis Kompetensi. Jakarta: GaungPersada.

Zemira R. Mevarech and Bracha Kramarski.1997. IMPROVE: A Multidimensional Method For Teaching Mathematics inHeterogeneous Classrooms. American Educational Research Journal. Diakses melalui http://aer.sagepub.com/content/34/2/365 pada tanggal 14 Agustus 2015 pukul 19.35 WIB.

Binti Maunah, Landasan Pendidikan, (Yogyakarta: Teras, 2009), hal. 5

Nini Subini, Psikologi Pembelajaran, (Yogyakarta: Mentari Pustaka, 2012), hal.6

Zainal Arifin Ahmad, Perencanaan Pembelajaran dari Design sampai Implementasi, (Yogyakarta: Pedagogia, 2012), hal. 8

Rini Handayani, PENERAPAN METODE IMPROVE DENGAN MENGGUNAKAN MEDIA KOMPUTER UNTUKMENINGKATKAN KOMUNIKASI MATEMATIKA SISWA, Surakarta, 2010.

Moch. Masykur Ag dan Abdul Halim Fathani,Mathematical Intelligence, (Jogjakarta: Ar-Ruzz Media, 2009), hal. 13 
Pengaruh Metode Improve terhadap Kreatifitas Kemampuan Komunikasi Matematis dan Hasil Belajar Siswa Kelas VII A MTS Syekh Subakir pada Materi Bangun Datar

Patmaningrum Agustin, "Penggunaan Metode Improve untuk Meningkatkan Hasil Belajar Mahasiawa pada Mata Kuliah kalkulus II", volume 4 No 1.

Sudrajat Akhmad, Media Pembelajaran Berbasis Komputer, (Jakarta: Artikel Pendidikan, 2010

Hodiyanto, "Kemampuan Komunikasi Matematis dalam Pembelajaran Matematika", dalam https://media.neliti.com/.../177556-ID-kemampuankomunikasi-matematis-dalam-pem..., diakses pada 26 Maret 2018 pukul 09:00 WIB.

Mery Ariska, Penerapan Metode Improve untuk Meningkatkan Hasil Belajar Siswa Kelas VIII SMPN 1 Singkil, (Banda Aceh: Skripsi full, 2017).

Rini Handayani, Penerapan Metode Improve dengan Menggunakan Media Komputer untuk Meningkatkan Komunikasi Matematika Siswa, (Surakarta: Foxit Pantom, 2010).

Sugiyono, METODE PENELITIAN PENDIDIKAN Pendekatan Kuantitatif, Kualitatif dan R\&D. (Bandung : Alfabeta, 2016), hal. 126. 